\title{
CRESCIMENTO VEGETATIVO DE ARROZ SOB DIFERENTES MANEJOS DE PRODUÇÕES ÉTNICAS NA GUINÉ-BISSAU
}

\section{Nelito Nhanca N'Bali'; ${ }^{1}$ Carlos Zacarias Joaquim Júnior²; Inácio João Barbosa ${ }^{3}$; Lamine Sanó $^{4}$; Domingos Djúr ${ }^{5}$ Fred Denílson Barbosa da Silva ${ }^{6}$; Daniela Zuliani Queiroz ${ }^{7}$}

\begin{abstract}
${ }^{1}$ Engenheiro Agrônomo, Udesc, Lages, Santa Catarina, ${ }^{2}$ Engenheiro Agrônomo, Unesp, Jaboticabal, São Paulo, ${ }^{3}$ Engenheiro Agrônomo, Unesp, Jaboticabal, São Paulo, ${ }^{4}$ Engenheiro Agrônomo, Udesc, Lages, Santa Catarina, ${ }^{5}$ Engenheiro Agrônomo, Unilab, Redenção, Ceará, ${ }^{6}$ Engenheiro Agrônomo, Unilab, Redenção, Ceará, ${ }^{7}$ Engenheira Agrônoma, Unilab, Redenção, Ceará.
\end{abstract}

DOI: 10.47094/ICONNECA.2021/5

\begin{abstract}
RESUMO
O arroz é um dos principais alimentos, senão, o mais consumido de toda a população guineenses, é a base alimentar da população. Com isso o trabalho visa identificar semelhanças e diferenças no desenvolvimento vegetativo da cultura, sob as diferentes técnicas de produção étnica. O delineamento experimental foi de blocos casualizados com 2 tratamentos e 5 repetições. Os blocos foram constituídos de seis canteiros para a técnica de produção da etnia balanta e para a etnia mandiga foi realizado em uma área com dimensão equivalente ao da outra técnica. Foram avaliados altura da planta e diâmetro de caule. Não houve significância entre os blocos. No entanto, foram observadas diferenças significativas nos dois manejos de cultivo de arroz para altura da planta, já no diâmetro do caule não houve diferença significativa. Dentre as técnicas trabalhadas a da etnia Balanta foi a que obteve maior desempenho da altura da planta.
\end{abstract}

PALAVRAS-CHAVE: Oryza sativa. Guiné-Bissau. Agricultura tradicional.

ÁREA TEMÁTICA: Outros.

\section{INTRODUÇÃO}

O arroz (Oryza sativa) é uma planta monocotiledônea da família Poaceae. É caracterizada de caules ocos, flores reduzidas de cor verde e aquênios especializados, ou cariopses, como frutos (EMBRAPA, 2000). A Guiné-Bissau tem uma grande diversidade étnico-cultural, com a presença de vários grupos étnicos, que partilham um único país, mas com hábitos de vida diferentes, dentre eles as Balantas e Mandingas, dois grupos étnicos com práticas culturais diferentes, principalmente nas práticas agrícolas, como no caso da produção de arroz (DJATA, et al., 2003).

O arroz é um dos principais alimentos, senão, o mais consumido de toda a população guineenses, ou seja, é a base alimentar da população, uma das fontes de renda familiar e de subsistência para a maioria dos produtores (MEDINA, 2008). O consumo de arroz por pessoa (per capita) é de 
aproximadamente $125 \mathrm{~kg} / \mathrm{ano}$, o que lhe faz ser comparado com alguns países de maior consumo. Neste sentido, o país depende fortemente da importação deste produto, sendo que a produção nacional cobre cerca de 50\% das necessidades alimentícias da população (BOCK, 2001).

O país possui das mais favoráveis condições naturais para a produção de arroz, assim como, a possibilidade de oferta em quantidades e qualidades com a expectativa do consumo, devido a favorável condição edafoclimática, onde a precipitação média anual situa entre 2.000 a $2500 \mathrm{~mm}$ e quase seis meses de chuvas, o que possibilita o cultivo do arroz inundado, assim como, o cultivo sequeiro em terras altas (DJATA et al. 2003).

O objetivo deste trabalho é de identificar semelhanças e diferenças no desenvolvimento vegetativo da cultura, sob as diferentes técnicas de produção étnica.

\section{MATERIAL E MÉTODOS}

O experimento foi instalado em uma área da Fazenda Experimental Piroás, da Universidade de Integração Internacional da Lusofonia Afro-Brasileira, localizada no distrito de Barra Nova, Sítio Piroás, município de Redenção, no Maciço de Baturité (04¹4’53” S; 3845’10” W; 240 m de altitude), durante o período de abril a julho de 2018. O clima da localidade é classificado como Aw, ou seja, tropical chuvoso, muito quente, com predomínio de chuvas nas estações do verão e do outono (KOPPEN, 1923).

O delineamento experimental foi de blocos casualizados com 2 tratamentos e 5 repetições. Os blocos foram constituídos de seis canteiros para a técnica de produção da etnia balanta e para a etnia mandiga foi realizado em uma área com dimensão equivalente ao da outra técnica. $\mathrm{O}$ uso de canteiro é uma prática que não é realizada pela etnia mandinga na produção de arroz, motivo pelo qual não houve levantamento de canteiros nesta técnica. Neste sentido, é importante ressaltar que a primeira técnica se refere ao transplantio de mudas em várzeas, inicialmente semeadas em viveiros e a segunda é o plantio direto em terras altas.

Foram construídos seis (6) canteiros com $5 \mathrm{~m}$ de comprimentos e $1 \mathrm{~m}$ de largura numa área de $80 \mathrm{~m}^{2}$ para cultivo da etnia Balanta, e a mesma área foi usada para o cultivo da etnia Mandinga. As mudas foram produzidas em cima dos canteiros construídos na área cobertas com solo através da semeadura a lanço de uma forma aleatória. Depois que as mudas completaram três semanas ou 21 dia após semeadura foram transplantadas no mesmo local com o espaçamento de $30 \mathrm{~cm}$ entre as plantas (figura 1).

Para avaliação do experimento, foi feita a coleta de uma amostra de 5 plantas ao acaso na área de cada canteiro. Foi avaliada a altura das plantas duas vezes durante todo o experimento, em um intervalo de 45 dias entre avaliações, a primeira avaliação foi feita aos 21 dias após a emergência e antes do transplante (para a técnica Balanta). A altura da planta foi estimada rente ao solo até a bainha foliar mais alta da planta, com o auxílio de uma trena e o diâmetro foi estimado entre a raiz e 
o primeiro nó, com o paquímetro digital.

Os dados foram submetidos a análise de normalidade de Shapiro e em seguida, a análise de variância pelo teste $\mathrm{F}$, após a significância dos dados, foi feito o teste de comparação das médias pelo teste Tukey a nível de 5\% de significância, pelo programa estatístico AgroEstat (versão 1.1.0).

Figura 1: Semeadura à lanço $(\mathrm{A})$ e transplantio $(\mathrm{B})$, no cultivo Balanta. Semeadura à lanço na área do cultivo Mandinga (C). UNILAB. Redenção-CE. 2019.
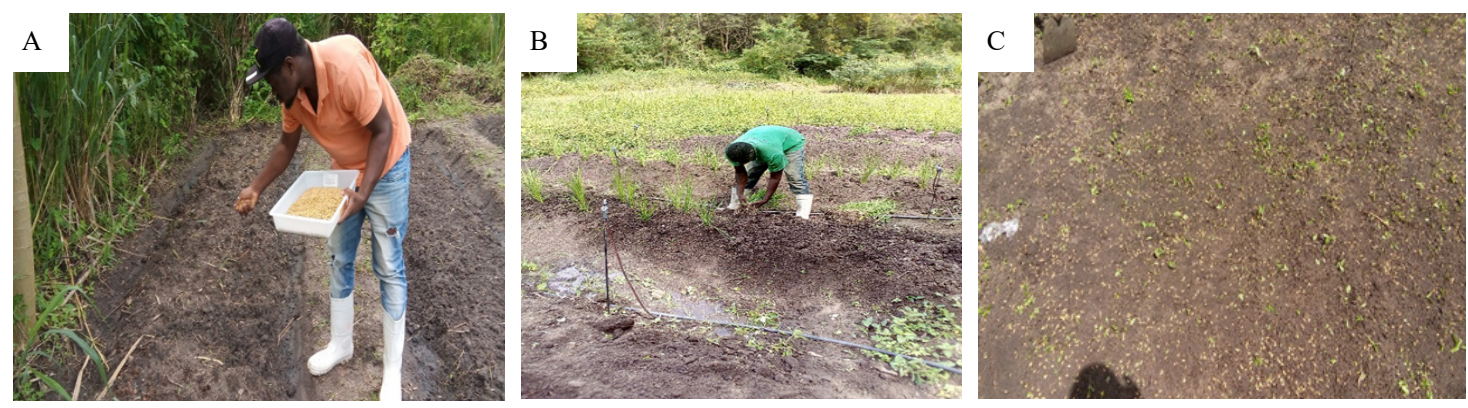

Fonte: N'Bali, 2019

\section{RESULTADOS E DISCUSSÃO}

Realizando a análise de variância pelo teste F, não houve significância entre os blocos, tanto na primeira avaliação, assim como, na segunda avaliação para ambas as técnicas. Para efeito de tratamentos, houve diferenças a nível de $5 \%$ de probabilidade para os dois modos de cultivo. No entanto, foram observadas diferenças significativas nos dois manejos de cultivo de arroz para altura da planta, já no diâmetro do caule não houve diferença significativa entre as duas técnicas, verificados em duas avaliações (tabela 1).

Tabela 1: Valores médios da altura da planta verificado em duas técnicas de cultivos tradicionais. UNILAB. RedençãoCE. 2019.

\begin{tabular}{|l|c|c|c|c|}
\hline \multirow{2}{*}{ Tratamentos } & \multicolumn{2}{|c|}{ Altura da planta $(\mathrm{cm})$} & \multicolumn{2}{c|}{ Diâmetro do caule $(\mathrm{mm})$} \\
\cline { 2 - 5 } & $1^{\mathrm{a}}$ avaliação & $2^{\mathrm{a}}$ avaliação & $1^{\mathrm{a}}$ avaliação & $2^{\mathrm{a}}$ avaliação \\
\hline Balanta & $42,3 \mathrm{a}$ & $101,9^{\mathrm{a}}$ & $4,3 \mathrm{a}$ & $6,7 \mathrm{a}$ \\
\hline Mandinga & $37,0 \mathrm{~b}$ & $85,6 \mathrm{~b}$ & $4,4 \mathrm{a}$ & $6,8 \mathrm{a}$ \\
\hline CV $(\%)$ & 5,36 & 6,31 & 2,78 & 1,90 \\
\hline
\end{tabular}

*Médias seguidas de mesma letra na mesma coluna não diferem entre si pelo teste Tukey a 5\% de probabilidade.

A diferença encontrada nas duas formas de cultivo, provavelmente se deve pelo fato de que o cultivo de arroz pela etnia Balanta, é realizado na zona onde há maior fluxo de água ou irrigação (zonas de várzeas), enquanto que a segunda técnica (Mandinga), é feita em terras altas, tendo menos 
presença de água no solo. Outro fator importante que deve influenciar essa diferença, foi que na técnica Balanta, os viveiros foram construídos em forma de leiras, tendo desta forma, o maior preparo do solo e menos compactado em relação a técnica Mandinga.

Os resultados encontrados na técnica Mandinga foram inferiores aos encontrados no trabalho desenvolvido por Silva et al. (2015), que ao avaliar o crescimento de cultivares de arroz de sequeiro sob aplicação de doses de silicato de cálcio, onde verificou-se aos 30 dias uma altura máxima de 57 cm e aos 60 dias uma altura máxima de $90 \mathrm{~cm}$. Já na técnica Balanta, foram inferiores na primeira avaliação e superiores na segunda como mostra a tabela 1.

Mesma situação a cima relatada, foi verificada no estudo realizado por Lange et al. (2016), avaliando fontes de fósforo na adubação corretiva em arroz de terras altas em cultivo de primeiro ano, verificaram que a altura máxima da planta observada foi de $90 \mathrm{~cm}$ ao final do ciclo, utilizando adubação de fosfato de arad.

\section{CONCLUSÃO}

Com relação as estimativas das médias da primeira avaliação, para altura da planta avaliadas na técnica da etnia Balanta foi em média, mais altas em ralação a técnica da etnia Mandinga. Também é possível observar que dentre as técnicas trabalhadas a da etnia Balanta foi a que obteve maior desempenho da altura da planta nas duas avaliações. É de salientar que as duas técnicas apresentaram boas médias, ou seja, de modo geral, as medias equivalentes a outros estudos verificados. Embora a altura da planta pode não influenciar diretamente a produtividade em alguns casos, mas pode influenciar indiretamente. É notável escassez de estudos sobre o tema neste país e na região, pelo que se faz necessário a realização de pesquisas na área, o que permitirá o maior conhecimento da cultura e da importância destas técnicas no cultivo de arroz.

\section{PRINCIPAIS REFERÊNCIAS}

BOCK, A. J. Segurança Alimentar: A cultura do Arroz e a Inovação Tecnológica na Guiné-

Bissau. Universidade Técnica de Lisboa. Instituto Superior de Agronomia. Lisboa, 2001.

DJATA, R. N.; MANÉ, A; INDÍ, M. Análise da Fileira do Arroz. Projeto de Reabilitação e Desenvolvimento do Sector Privado. Guiné-Bissau, 2003.

EMBRAPA, Agência Embrapa de Informação Tecnológica. Características Morfológicas do Arroz. 2000. Disponível:https://www.agencia.cnptia.embrapa.br/gestor/arroz/arvore/ CONT000fe 75wint02wx5eo07qw4xeclygdut.html. Acesso: 12/05/2021.

LANGE, A.; DIEL, D.; CARVALHO, F. F.; MACHADO, R. A. F.; ZANUZO, M. R.; SILVA, A.; BUCHELT, A. C. Fontes de Fósforo na Adubação Corretiva em Arroz de Terras Altas em Cultivo 
de Primeiro Ano. R. Ciênc. Agroamb., v.14, n.1, p.67-75, 2016.

MEDINA, N. O Ecossistema Orizícola na Guiné-Bissau: Principais Constrangimentos à Produção na Zona I (Regiões de Biombo, Cacheu e Oio) e Perspectivas. Dissertação de Mestrado (Universidade Técnica de Lisboa-ISA), Lisboa, 2008.

SILVA, V. F. A.; MELO, N. C.; GOMES, R. F.; VALENTE, G. F.; FERREIRA, R. L. C. Crescimento de Cultivares de Arroz de Sequeiro sob Aplicação de Doses de Silicato de Cálcio. Enciclopédia Biosfera, Centro Científico Conhecer - Goiânia, v.11, n.21, p. 1-9, 2015. 